\title{
Clarifying the Relationship of Parental Bonding to Suicide Ideation and Attempts
}

\author{
Boaz Y. Saffer, BA, Catherine R. Glenn, PhD, and E. David Klonsky, PhD
}

\begin{abstract}
Suicide and suicidal behavior are major public health problems, especially among adolescents and young adults. Previous research has established links between parental bonding and suicidality; however, it remains unclear whether parental bonding is associated with suicide ideation, the progression from suicide ideation to suicide attempts, or both. This study examined the relation of parental bonding to suicide ideation and suicide attempts in adolescents from two settings: (1) acute psychiatric care $(n=172)$ and (2) high school $(n=426)$. All participants were administered validated measures of parental bonding, suicide ideation, and suicide attempts, as well as emotion dysregulation, loneliness, and self-worth. In the psychiatric sample, lower parental care significantly differentiated adolescents with a history of suicide attempts from those with suicide ideation only or without histories of suicidality. This pattern remained even after controlling for other known correlates of suicidality (i.e., emotional dysregulation, loneliness, and low self-worth). Similar effects were found in the community sample, although these findings failed to reach statistical significance. In both samples, parental overprotection was not associated with suicide ideation or suicide attempts. Results suggest that parental care may be an important risk factor for youth suicidal behavior and may help differentiate suicide attempters from suicide ideators.
\end{abstract}

Suicide is the third leading cause of death among adolescents (World Health Organization, 1999) and the primary cause of death among females 15 to 19 years of age (Patton et al., 2009). Adolescents worldwide are more likely to die by suicide than any medical illness or disease (Patton et al., 2009). In the United States, approximately $12 \%$ of adolescents report having thought about attempting suicide and $4 \%$ have

BOAZ Y. SAFFER, The University of British Columbia, Vancouver, BC, Canada; CATHerine R. GLenn, Harvard University, Cambridge, MA, USA; E. DAvID KLONSKY, The University of British Columbia, Vancouver, BC, Canada. Address correspondence Boaz Y. Saffer, 2136 West Mall, University of British Columbia, Vancouver, BC V6T 1Z4, Canada. E-mail: boazsaffer@hotmail.com made a nonfatal suicide attempt (Nock, Green, et al., 2013). Given that adolescent suicide rates in the United States and around the world remain high (Nock, Borges, et al., 2008; Nock, Green, et al., 2013), improving our understanding of risk factors associated with suicidal thoughts and behaviors is therefore crucial to predict and prevent suicide attempts.

Previous research indicates that adverse family experiences such as parental separation or divorce (Gould, Shaffer, Fisher, \& Garfinkel, 1998), marital discord (Fergusson \& Lynskey, 1995), and physical punishment (Fergusson \& Lynskey, 1997) increase the risk for suicide in adolescents (Beautrais, 2000). Furthermore, several studies have found that completed and attempted suicide rates are increased in 
adolescents exposed to parental psychopathology (Brent et al., 1994; Gould, Fisher, Parides, Flory, \& Shaffer, 1996; Pfeffer, Normandin, \& Kakuma, 1994). Common to these risk factors is the quality of the parent-adolescent relationship which, if negatively impacted, may increase the risk for suicide. Indeed, a growing literature implicates maladaptive parental bonding as an important risk factor for adolescent suicidal behavior (Adam, Keller, West, Larose, \& Goszer, 1994; Beautrais, Joyce, \& Mulder, 1996; Goldney, 1985; Martin \& Waite, 1994; Tousignant, Bastien, \& Hamel, 1993). These studies utilize the parental bonding instrument (PBI), which assesses two dimensions of parental bonding: parental care (sample item: my parent "appeared to understand my problems and worries") and overprotection (sample item: my parent "was overprotective of me"; Parker, Tupling, \& Brown, 1979). A recent metaanalysis of 12 studies (Goschin, Briggs, Blanco-Lutzen, Cohen, \& Galynker, 2013) found that suicide ideation and suicide attempts in adolescents were associated with low parental care and high overprotection. Effects were largest for low parental care and particularly low maternal care.

Notably, while these studies of parental bonding and suicide ideation and suicide attempts provide valuable information, they are limited in a particular respect. Among the 12 studies reviewed by Goschin et al. (2013), only one specifically compared adolescents with a history of suicide attempts to adolescents who had suicide ideation but never acted on their thoughts. This distinction is critical because most adolescent (and adult) ideators do not go on to make a suicide attempt (Fergusson, Beautrais, \& Horwood, 2003; Nock, Green, et al., 2013; Ten Have et al., 2009), because oft-cited risk factors for suicide distinguish poorly between those who attempt suicide and those who only consider suicide (Klonsky \& May, 2014). In the one study on parental bonding to compare attempters to ideators who had not attempted (henceforth, referred to as "ideators"), Adam et al. (1994) found that adolescent psychiatric outpatients with a history of suicide attempts reported lower maternal care and higher maternal overprotection than adolescent ideators. Adam et al. did not report the corresponding analysis for paternal care or overprotection. To our knowledge, no other study has examined parental bonding differences between adolescent attempters and ideators. Thus, identifying variables that may help make this distinction is important for both suicide theory and prevention.

This study was designed to address this knowledge gap. Specifically, we utilized two adolescent samples-one psychiatric and one community - to compare parental bonding scores among three groups: suicide attempters, suicide ideators, and adolescents with no history of either suicide ideation or suicide attempts. In addition, we examined other variables previously associated with suicidal behavior as potential mediators of this relationship. These variables were emotion dysregulation (Zlotnick, Donaldson, Spirito, \& Pearlstein, 1997), loneliness (Roberts, Roberts, \& Chen, 1998; Wichstrøm, 2000), and self-worth (Grøholt, Ekeberg, Wichstrøm, \& Haldorsen, 2000).

\section{METHODS}

\section{Sample 1. Adolescents Receiving Acute Psychiatric Care}

\section{Participants and Procedure}

Participants were 172 adolescent psychiatric patients recruited from the inpatient and partial hospitalization units at a large hospital in the northeastern United States that provides short-term treatment for adolescents with severe psychopathology. Parental consent and participant assent were obtained prior to the administration of the study protocol. Adolescents were excluded from the study only if they were unable to complete the protocol due to psychosis, 
aggressive behavior, cognitive deficits, or suicide-related behavior that the staff deemed too extreme for study participation. Average age of participants was $15.04(S D=1.39)$. The sample was $77 \%$ female, $68 \%$ Caucasian, 10\% African American, 21\% Hispanic, and $1 \%$ Asian.

Regarding a history of suicide attempts, 71 adolescents had previously attempted suicide and 56 adolescents stated that their most recent suicide attempt had occurred in the past 12 months. Of these recent attempters, 28 reported a single suicide attempt, 17 reported two to three suicide attempts, 8 reported four to five suicide attempts, and 3 reported six or more suicide attempts. Of the 15 adolescents with a history of suicide attempts occurring earlier than the past 12 months, four reported experiencing suicide ideation during the past 12 months. Regarding suicide ideation, 38 adolescents reported a history of suicide ideation but no history of attempts. Of these ideators, 27 adolescents reported thinking about suicide in that past 12 months. The remaining 63 participants did not endorse a history of suicide ideation or past suicide attempt.

\section{Measures}

Emotion Dysregulation. Emotion dysregulation was assessed using the Difficulties in Emotion Regulation Scale (DERS; Gratz \& Roemer, 2004). The scale includes 36 items which assess difficulties regulating emotion across six domains: (1) nonacceptance, (2) goals, (3) impulse, (4) awareness, (5) strategies, (6) and clarity. Participants indicate on a Likert scale ranging from 1 (almost never) to 5 (almost always) how often each item applies to themselves. Higher scores indicate greater emotion dysregulation. The DERS has been validated in both adult (Gratz \& Roemer, 2004) and adolescent samples (Weinberg \& Klonsky, 2009), demonstrating good internal consistency and test-retest reliability (Tull \& Roemer, 2007). In the current sample, the internal consistency ranged from 0.80 to 0.90 for the DERS subscales and was .95 for the DERS total score.

Loneliness. Loneliness was measured using a 10-item version of the UCLA Loneliness Scale (UCLA-LS; Russell, Peplau, \& Cutrona, 1980). The scale has been validated in several studies using adolescent samples including those with a history of self-harming behavior (Nock \& Prinstein, 2005) and suicide attempts (Guertin, Lloyd-Richardson, Spirito, Donaldson, \& Boergers, 2001), demonstrating good test-retest and split-half reliability as well as internal consistency (Hartshorne, 1993; Vassar \& Crosby, 2008). The UCLA-LS is also highly correlated with other measures of loneliness, suggesting high convergent validity (Russell, 1996). The internal consistency of the UCLA-LS in this sample is .90 .

Parental Bonding. A modified sevenitem version of the parental bonding instrument (PBI) was used to assess quality of parental bonding (Parker et al., 1979; Todd, Boyce, Heath, \& Martin, 1994). Four items assess parent overprotection and three items measure parental care. Items are completed twice, once to assess maternal bonding and again to measure paternal bonding. Participants indicate on a Likert scale ranging from 1 (Not at all) to 4 (A lot) how representative each item is of either their mother or father. The PBI has high short-term reliability (Parker, 1990) and has been found to be stable over 20 years (Wilhelm, Niven, Parker, \& Hadzi-Pavlovic, 2005). The abbreviated seven-item version of the PBI used in this study has demonstrated good internal reliability and strong correlations with the full-length PBI (Todd et al., 1994) and thereby represents a valid and time-efficient measure of parental bonding.

Because Cronbach's alpha can underestimate reliability for scales composed of just a few items, utilizing alternate measures of reliability for short scales is recommended (Whitley \& Kite, 2013). Therefore, we report the item-total correlations in addition to coefficient alpha. Coefficient alphas for the maternal care and overprotection scales were good (.71) and low (.49), 
respectively; item-total correlations for both scales were good (median $=.38$, range $=.25-.59$ ). Coefficient alphas for the paternal care and overprotection scales were good (.68) and fair (.53), respectively; the item-total correlations were good $($ median $=$ 2.42 , range $=.24-.55$ ).

Self-Worth. The Self-Perception Profile for Adolescents (SPPA; Harter, 1988) is a 45 -item questionnaire that assess adolescents' self-perception across nine subscales: (1) scholastic competence, (2) social competence, (3) athletic competence, (4) physical appearance, (5) job competence, (6) romantic appeal, (7) behavioral conduct, (8) close friendship, and (9) global self-worth. Selfworth was assessed using the five-item global self-worth (SPPA-GSW) subscale of the SPPA. We utilized the version of the SPPA validated by Wichstrøm (1995). For every question, participants were presented with a single statement such as "Some teenagers like the way they are leading their life." Participants report how representative each statement is of themselves on a scale from 1 (Describes me very poorly) to 4 (Describes me very well). Good-excellent internal consistency has been reported for the global selfworth subscale of the SPPA (Harter, 2012). Cronbach's alpha for the SPPA-GSW in this sample was .78.

Suicide Ideation and Attempts. The Youh Risk Behaviour Survey (YRBS; Grunbaum et al., 2002; Kolbe, Kann, \& Collins, 1993) is a large-scale survey administered in the United States by the Center for Disease Control to assess health risk behaviors in high school students. The survey is administered semi-annually to a nationally representative sample. The YRBS suicide questions have demonstrated good test-retest reliability and convergent and discriminant validity (Brener et al., 2002; May \& Klonsky, 2011).

A history of lifetime suicide attempt was assessed by the item: "Have you ever tried to kill yourself?" Participants who endorsed this item were categorized as suicide attempters. Lifetime suicide ideation was determined to be present if participants answered "yes" to the item: "Have you ever seriously thought about killing yourself?" Participants who endorsed this item and did not endorse a history of suicide attempt were classified as suicide ideators. Participants who endorsed neither questions were categorized as nonsuicidal participants.

A history of suicide attempt in the preceding 12 months was assessed by the item "During the past 12 months, how many times did you actually attempt suicide?" Participants who endorsed one or more suicide attempts were categorized as recent attempters. Past year suicide ideation was determined to be present if participants answered "yes" to the item: "During the past 12 months, did you ever seriously consider attempting suicide?" Participants who endorsed this item were categorized as recent ideators. Participants who did not report a history of both suicide attempt and ideation in the preceding 12 months were categorized as recent nonsuicidal participants.

\section{Sample 2. Adolescents Attending High School}

\section{Participants and Procedure}

Sample 2 consisted of adolescents in Grades 9 through 12 attending a large high school in the northeastern United States. Parental permission and informed assent from the participating students were obtained prior to the administration of the study protocol. Of the 700 students invited to participate, 413 completed the study. The sample was approximately $61 \%$ female, $53 \%$ Caucasian, $19 \%$ Hispanic, $15 \%$ Asian, $11 \%$ African American, and 3\% mixed racial heritage. Age ranged from 13 to 17 years. (Demographic information was only available for the larger population of 700).

Regarding a history of suicide attempts, 23 adolescents had previously attempted suicide and 14 adolescents reported a suicide attempt within the past 12 months. Of these attempters, eight reported a single suicide 
attempt, four reported two to three suicide attempts, one reported four to five suicide attempts, and one reported six or more suicide attempts. Of the nine adolescents with a history of suicide attempt occurring earlier than the past 12 months, seven endorsed suicide ideation within the past 12 months. Regarding suicide ideation, 48 adolescents reported a history of suicide ideation but no history of attempts. Of these ideators, 22 reported thinking about suicide within the past 12 months. The remaining 355 participants did not endorse a history of suicide ideation or past suicide attempts.

\section{Measures}

All measures are identical to those used for Sample 1. Coefficient alphas were .93 for the DERS, .88 for the UCLA-LS, and .82 for the SPPA-GSW scale. For the
PBI, coefficient alphas for the maternal care and overprotection scales were good (.69) and low (.46), respectively; the item-total correlations were good (median $=.30$, range $=.23-.59)$. Coefficient alphas for the paternal care and overprotection scales were fair (.53) and low (.38), respectively; the item-total correlations were good (median $=.29$, range $=.12-.59)$.

\section{RESULTS}

Descriptive statistics for all variables analyzed are provided in Table 1. A oneway analysis of variance (ANOVA) with LSD post hoc tests was conducted in each sample to compare parental bonding scores among suicide attempters, suicide ideators, and nonsuicidal participants. Effect sizes for group comparisons, as well as inferential statistics, are presented in Table 2.

TABLE 1

Measures Scores Across Groups

\begin{tabular}{|c|c|c|c|c|c|c|}
\hline & \multicolumn{2}{|c|}{ Not Suicidal } & \multicolumn{2}{|c|}{ Ideators } & \multicolumn{2}{|c|}{ Attempters } \\
\hline & Mean & $S D$ & Mean & $S D$ & Mean & $S D$ \\
\hline \multicolumn{7}{|c|}{ Psychiatric Sample } \\
\hline \multicolumn{7}{|l|}{ PBI Mother } \\
\hline Care & 9.80 & 2.42 & 10.36 & 2.15 & 8.12 & 2.67 \\
\hline Overprotection & 9.48 & 2.32 & 9.09 & 2.74 & 9.72 & 2.94 \\
\hline \multicolumn{7}{|l|}{ PBI Father } \\
\hline Care & 8.55 & 2.57 & 8.80 & 2.83 & 7.43 & 2.67 \\
\hline Overprotection & 8.77 & 2.94 & 8.77 & 2.47 & 9.32 & 3.07 \\
\hline DERS & 88.13 & 28.19 & 110.64 & 24.34 & 114.26 & 29.71 \\
\hline SPPA-GSW & 14.15 & 3.63 & 12.69 & 3.22 & 10.52 & 3.59 \\
\hline UCLA-LS & 21.40 & 6.02 & 26.89 & 5.94 & 26.63 & 6.66 \\
\hline \multicolumn{7}{|c|}{ Community Sample } \\
\hline \multicolumn{7}{|c|}{ PBI Mother } \\
\hline Care & 10.30 & 2.03 & 9.06 & 2.62 & 8.30 & 2.55 \\
\hline Overprotection & 8.81 & 2.38 & 8.65 & 2.23 & 9.13 & 2.74 \\
\hline \multicolumn{7}{|l|}{ PBI Father } \\
\hline Care & 9.90 & 2.14 & 8.66 & 2.55 & 7.35 & 2.91 \\
\hline Overprotection & 8.29 & 2.31 & 8.21 & 2.07 & 9.2 & 2.14 \\
\hline DERS & 75.15 & 21.25 & 96.60 & 23.97 & 99.70 & 22.72 \\
\hline SPPA-GSW & 16.20 & 2.98 & 12.94 & 3.23 & 12.70 & 3.47 \\
\hline UCLA-LS & 18.61 & 5.22 & 23.30 & 5.49 & 24.09 & 5.47 \\
\hline
\end{tabular}

DERS = Difficulties in Emotion Regulation Scale; PBI = Parental Bonding Instrument; SPPAGSW = Self-Perception Profile for Adolescents - Global Self-Worth; UCLA-LS = UCLA Loneliness Scale. 
TABLE 2

Differences Between Nonsuicidal Adolescents, Ideators, and Attempters

\begin{tabular}{|c|c|c|c|c|c|}
\hline & \multirow{2}{*}{$\begin{array}{c}\begin{array}{c}\text { Nonsuicidal Versus } \\
\text { Ideators }\end{array} \\
d(.95 \mathrm{CI})\end{array}$} & \multirow{2}{*}{$\begin{array}{c}\begin{array}{c}\text { Nonsuicidal Versus } \\
\text { Attempters }\end{array} \\
d(.95 \mathrm{CI})\end{array}$} & \multirow{2}{*}{$\begin{array}{c}\begin{array}{c}\text { Ideators Versus } \\
\text { Attempters }\end{array} \\
d(.95 \mathrm{CI})\end{array}$} & \multicolumn{2}{|c|}{$\begin{array}{l}\text { ANOVA } \\
\text { Across } 3 \\
\text { Groups }\end{array}$} \\
\hline & & & & $F$ & $p$ \\
\hline \multicolumn{6}{|c|}{ Psychiatric Sample } \\
\hline \multicolumn{6}{|l|}{ PBI Mother } \\
\hline Care & $0.25(-0.24$ to 0.73$)$ & $0.66(0.20$ to 1.13$)$ & $0.91(0.41$ to 1.41$)$ & 10.89 & $<.001$ \\
\hline Overprotection & $0.16(-0.37$ to 0.69$)$ & $0.09(-0.40$ to 0.59$)$ & $0.22(-0.35$ to 0.80$)$ & 0.59 & $>.5$ \\
\hline \multicolumn{6}{|l|}{ PBI Father } \\
\hline Care & $0.09(-0.49$ to 0.68$)$ & $0.43(-0.07$ to 0.93$)$ & $0.51(-0.07$ to 1.09$)$ & 3.42 & $<.05$ \\
\hline Overprotection & $0.00(-0.61$ to 0.61$)$ & $0.19(-0.39$ to 0.76$)$ & $0.20(-0.41$ to 0.80$)$ & 0.60 & $>.5$ \\
\hline DERS & $0.85(-4.56$ to 6.26$)$ & $0.91(-4.18$ to 6.00$)$ & $0.13(-5.22$ to 5.48$)$ & 14.45 & $<.001$ \\
\hline SPPA-GSW & $0.42(-0.28$ to 1.13$)$ & $1.01(0.37$ to 1.65$)$ & $0.63(-0.04$ to 1.30$)$ & 16.03 & $<.001$ \\
\hline UCLA-LS & $0.93(-0.29$ to 2.14$)$ & $0.83(-0.31$ to 1.96$)$ & $0.04(-1.20$ to 1.29$)$ & 12.77 & $<.001$ \\
\hline \multicolumn{6}{|c|}{ Community Sample } \\
\hline \multicolumn{6}{|l|}{ PBI Mother } \\
\hline Care & $0.59(0.38$ to 0.80$)$ & 0.97 (0.76 to 1.18$)$ & $0.30(-0.30$ to 0.90$)$ & 15.12 & $<.001$ \\
\hline Overprotection & $0.07(-0.17$ to 0.30$)$ & $0.13(-0.11$ to 0.38$)$ & $0.20(-0.36$ to 0.76$)$ & 0.31 & $>.5$ \\
\hline \multicolumn{6}{|l|}{ PBI Father } \\
\hline Care & $0.57(0.35$ to 0.79$)$ & $1.17(0.94$ to 1.39$)$ & $0.50(-0.14$ to 1.14$)$ & 17.01 & $<.001$ \\
\hline Overprotection & $0.03(-0.20$ to 0.26$)$ & $0.40(-0.16$ to -0.64$)$ & $0.48(-0.03$ to 0.99$)$ & 1.58 & $>.2$ \\
\hline DERS & $1.00(-1.12$ to 3.11$)$ & $1.15(-1.00$ to 3.31$)$ & $0.13(-5.27$ to 5.54$)$ & 31.93 & $<.001$ \\
\hline SPPA-GSW & $1.09(0.79$ to 1.39$)$ & $1.17(0.86$ to 1.48$)$ & $0.07(-0.69$ to 0.84$)$ & 35.26 & $<.001$ \\
\hline UCLA-LS & $0.90(0.37$ to 1.42$)$ & $1.05(0.51$ to 1.59$)$ & $0.15(-1.12$ to 1.41$)$ & 25.77 & $<.001$ \\
\hline
\end{tabular}

Note: Based on LSD post hoc tests, all effect sizes greater than.43 in the psychiatric and .57 in the community sample are statistically significant at $p<.05$. DERS $=$ Difficulties in Emotion Regulation Scale; PBI = Parental Bonding Instrument; SPPA-GSW = Self-Perception Profile for Adolescents Global Self-Worth; UCLA-LS = UCLA Loneliness Scale.

In the psychiatric sample, as indicated in Table 2, PBI maternal and paternal care scores significantly differed among the three groups. Examining between-group differences revealed that adolescents with a history of suicide attempts scored significantly lower on both maternal and paternal care scales than adolescents with a history of suicide ideation but no history of attempts, $t(143)=4.19$ and $t(130)=2.26$, respectively. Suicide attempters also demonstrated significantly lower maternal and paternal care scores than nonsuicidal adolescents, $t(143)=3.61$ and $t(130)=2.13$, respectively. In contrast, suicide ideators did not significantly differ from nonsuicidal adolescents on either maternal or paternal care scales, $t(143)=1.04$ and $t(130)=0.40$, respectively. No significant differences in either maternal or paternal overprotection scores were observed between suicide attempters and suicide ideators, $t(141)=1.1$ and $t$ $(130)=0.85$; suicide attempters and nonsuicidal participants, $t(141)=0.47$ and $t(130)=$ 0.97; as well as nonsuicidal participants and suicide ideators, $t(141)=0.64$ and $t(130)=$ 0.00 .

In the community sample, as indicated in Table 2, a one-way ANOVA determined that PBI maternal and paternal care scores significantly differed among groups. Suicide attempters reported significantly lower maternal and paternal care scores than nonsuicidal adolescents, $t(24)=3.68$ and $t(20)=3.89$, respectively, and lower maternal and paternal care compared with suicide ideators, $t(45)=1.16$ and $t(33)=1.73$, respectively. Further, participants with a 
history of suicide ideation had significantly lower maternal and paternal care scores than nonsuicidal participants, $t(54)=3.11$ and $t(51)=3.08$, respectively. No significant differences on either maternal or paternal overprotection scores were found when comparing suicide attempters to suicide ideators, $t(410)=0.79$ and $t(390)=1.60$; suicide attempters to nonsuicidal participants, $t(410)=0.62$ and $t(390)=1.74$; as well as nonsuicidal participants to suicide ideators, $t(410)=0.43$ and $t(390)=0.20$.

Next, we examined group differences in emotion dysregulation, global self-worth, and loneliness in both the psychiatric and community adolescent samples (Table 2). In the psychiatric sample, suicide attempters and suicide ideators reported significantly greater emotion dysregulation, $t(156)=3.8$ and $t(156)=5.15$, and loneliness, $t(152)=$ 4.01 and $t(152)=4.53$, than nonsuicidal participants. Suicide attempters also reported significantly lower global self-worth scores than either suicide ideators or nonsuicidal participants, $t(153)=3.0$ and $t(153)=5.6$, respectively. No significant differences between suicide attempters and suicide ideators were found on either emotion dysregulation or loneliness, $t(156)=0.625$ and $t(152)=0.20$, respectively. Suicide ideators did not significantly differ from nonsuicidal participants on measures of global selfworth. ${ }^{1}$

In the community sample, nonsuicidal participants reported significantly less emotion dysregulation and loneliness than adolescents with a history of suicide attempt, $t(419)=5.27$ and $t(402)=4.83$, or suicide ideation, $t(419)=6.44$ and $t(402)=$ 5.72. Nonsuicidal participants reported greater global self-worth than adolescents with a history of suicide attempts, $t(409)=$ 5.36 , or suicide ideation, $t(409)=6.91$. No significant differences between suicide attempters and suicide ideators were found

\footnotetext{
${ }^{1}$ In this sample, the pattern of results was similar for measures of depression, anxiety, and stress (i.e., the DASS-21; Antony, Bieling, Cox, Enns, \& Swinson, 1998).
}

on either emotion dysregulation, $t(419)=$ 0.56 , global self-worth, $t(409)=0.31$, or loneliness, $t(402)=0.59$.

To better understand the difference between attempters and ideators on parental care, partial point-biserial correlations were computed between group status (attempter vs. ideators) and parental care while controlling for emotional dysregulation, loneliness, and global self-worth. In the psychiatric sample, differences between attempters and ideators on both maternal and paternal care scores persisted above and beyond the three covariates, $r_{p b}(83)=-.47$, $p<.001$ and $r_{p b}(75)=-.24, p<.05$, respectively. In the community sample, the partial point-biserial correlation for maternal care was lower than in the psychiatric sample, $r_{p b}(62)=-.13, p=.30$, but was similar for paternal care compared with the psychiatric sample, $r_{p b}(56)=-.25, p=.06$.

We conducted partial point-biserial correlational analyses to examine differences in PBI scores between ideators and nonsuicidal adolescents. Across both samples, only one of the correlations was significant and none were greater than a magnitude of $r_{p b}=18$.

Finally, the same analyses were conducted using groups restricted to suicide attempts and suicide ideation occurring in the past 12 months. The results replicate the pattern of findings reported earlier regarding the relationship of PBI scales to suicide ideation and are available upon request from the authors.

\section{DISCUSSION}

In this study we examined the association between parental bonding and histories of suicide ideation and attempts in two adolescent samples. Previous studies have found that low parental care and high overprotection are associated with adolescent suicidality in general. However, these studies did not elucidate whether parental bonding is associated with a history of suicide ideation, suicide attempts, or both. Therefore, this study is novel in its comparison of 
parental bonding among adolescents with histories of attempts, histories of ideation without attempts, and no history of either suicide ideation or suicide attempts.

In our psychiatric sample of adolescents, lower parental care distinguished suicide attempters from both suicide ideators and controls. Specifically, adolescents with a history of suicide attempts reported lower maternal and paternal care scores than adolescents with a history of suicide ideation. This relationship remained even when accounting for other suicide risk factors such as emotion dysregulation, loneliness, and global self-worth. The direction and magnitude of effects were similar in our community sample of adolescents, although these effects did not reach statistical significance.

In contrast, when comparing ideators to nonsuicidal adolescents, in both samples, the parental care differences were smaller, and these relationships did not persist when accounting for emotion dysregulation, loneliness, and self-worth. Finally, in both psychiatric and community samples, parental overprotection did not differ across attempters, ideators, and nonsuicidal adolescents.

These findings have practical and theoretical implications for understanding suicide risk in adolescent populations. One aim of suicide risk assessments is to identify which ideators are at risk for acting on their suicidal thoughts so as to predict and prevent suicide attempts. However, it has recently become clear that most variables included in risk assessments - including psychiatric diagnosis, hopelessness, and impulsivity-provide little information about differences between who considers suicide without attempting and who acts on their suicidal thoughts; instead, these variables predict the presence of suicide ideation (Klonsky \& May, 2014). Similarly, in the present study, emotion dysregulation and loneliness were found to predict suicide ideation, but not to distinguish attempters from ideators. In contrast, the present study showed that parental bonding may help differentiate suicide attempters from suicide ideators. The relationship of parental bonding to suicide attempt history held even when accounting for other suicide risk factors.

These findings inform theories of suicide seeking to develop more specific and accurate explanations regarding the progression from suicide ideation to suicide attempts. For example, recent theories have begun to offer separate explanations and lists of risk factors for the development of suicide ideation versus progression from ideation to attempts (Joiner, 2005; Klonsky \& May, 2014; O'Connor, 2011). In particular, Joiner's interpersonal-psychological theory (Joiner, 2005) suggests that suicide risk is increased when an individual acquires the capability for suicide, experiences thwarted belongingness, and believes themselves to be a burden to others. Lack of parental affection (low parental care) might contribute to a sense of both low-belongingness and burdensomeness in adolescents, thereby increasing one's desire for suicide. However, linking parental care to burdensomeness and belongingness addresses why parental care contributes to suicide ideation but not why parental care would be lower in attempters compared with ideators, as found in the present study. One possible explanation for this finding is that compromised parental care may contribute to developmental deficiencies such as impaired problem solving (Matheson et al., 2005) which, in turn, may make adolescents with ideation less prone to finding adaptive solutions to their problems and more prone to acting on their suicidal thoughts. A second possibility is that parental care indicates increased connectedness with one's parent and that this connectedness may represent a reason to live which precludes progression from ideation to an actual attempt (Malone et al., 2000). However, we offer these possibilities as tentative speculations; it is important for future research to clarify the impact of parental care on suicidal behavior.

This study has several limitations. First, we utilized self-report measures to 
assess constructs of interest. The validity of self-report can be limited if participants are unable or unwilling to fully and accurately disclose their experiences. Future studies can incorporate additional sources of information, including semistructured interviews, as well as informant and chart-based sources to further assess suicide ideation and suicide attempt. In addition, an abbreviated version of the PBI was used and low internal consistency was found for the overprotection scale, potentially limiting the findings using this scale. Although the abbreviated version of the PBI has been shown to correlate highly with the full-length instrument (Todd et al.,

\section{REFERENCES}

Adam, K. S., Keller, A., West, M., Larose, S., \& Goszer, L. B. (1994). Parental representation in suicidal adolescents: A controlled study. The Australian and New Zealand Fournal of Psychiatry, 28, 418-425. doi:10.3109/00048679409075868

Antony, M. M., Bieling, P. J., Cox, B. J., Enns, M. W., \& Swinson, R. P. (1998). Psychometric properties of the 42-item and 21-item versions of the Depression Anxiety Stress Scales in clinical groups and a community sample. Psychological Assessment, 10, 176-181. doi:10.1037//1040-3590.10.2.176

Beautrais, A. L. (2000). Risk factors for suicide and attempted suicide among young people. The Australian and New Zealand fournal of Psychiatry, 34, 420-436. doi:10.1080/j.14401614.2000.00691.x

Beautrais, A. L., Joyce, P. R., \& MulDER, R. T. (1996). Risk factors for serious suicide attempts among youths aged 13 through 24 years. Fournal of the American Academy of Child and Adolescent Psychiatry, 35, 1174-1182. doi:10.1097/00004583-199609000-00015

Brener, N. D., Kann, L., McManus, T., Kinchen, S. A., Sundberg, E. C., \& Ross, J. G. (2002). Reliability of the 1999 Youth Risk Behavior Survey Questionnaire. The Fournal of Adolescent Health: Official Publication of the Society for Adolescent Medicine, 31, 336-342.

Brent, D. A., Perper, J. A., Moritz, G., Liotus, L., Schweers, J., Balach, L., ET al. (1994). Familial risk factors for adolescent suicide: A case-control study. Acta Psychiatrica Scandinavica, 89, 52-58.

Fergusson, D. M., Beautrais, A. L., \& Horwood, L. J. (2003). Vulnerability and resil-
1994), using the full version of the PBI would increase measurement reliability, and thereby more accurately estimate the relationship between parental bonding and suicide attempt. Third, because this study is retrospective rather than prospective in nature, findings are correlational, and it is not possible to determine whether parental bonding experiences influenced suicidality, whether suicidality influenced parental bonding, or whether third variables influenced both. Future research could partially address this limitation through longitudinal designs in which parental bonding measures are used to predict future suicidality.

iency to suicidal behaviours in young people. Psychological Medicine, 33, 61-73.

Fergusson, D. M., \& Lynskey, M. T. (1995). Childhood circumstances, adolescent adjustment, and suicide attempts in a New Zealand birth cohort. Fournal of the American Academy of Child and Adolescent Psychiatry, 34, 612622. doi:10.1097/00004583-199505000-00013

Fergusson, D. M., \& Lynskey, M. T. (1997). Physical punishment/maltreatment during childhood and adjustment in young adulthood. Child Abuse \& Neglect, 21, 617-630.

Goldney, R. D. (1985). Parental representation in young women who attempt suicide. Acta Psychiatrica Scandinavica, 72, 230-232.

Goschin, S., Briggs, J., Blanco-Lutzen, S., Cohen, L. J., \& Galynker, I. (2013). Parental affectionless control and suicidality. Fournal of Affective Disorders, 151, 1-6. doi:10.1016/j.jad. 2013.05.096

Gould, M. S., Fisher, P., Parides, M., Flory, M., \& Shaffer, D. (1996). Psychosocial risk factors of child and adolescent completed suicide. Archives of General Psychiatry, 53, 1155-1162. doi:10.1001/archpsyc.1996.01830120095016

Gould, M. S., Shaffer, D., Fisher, P., \& Garfinkel, R. (1998). Separation/divorce and child and adolescent completed suicide. Fournal of the American Academy of Child and Adolescent Psychiatry, 37, 155-162. doi:10.1097/00004583199802000-00007

Gratz, K. L., \& Roemer, L. (2004). Multidimensional assessment of emotion regulation and dysregulation: Development, factor structure, and initial validation of the difficulties in emotion regulation scale. Fournal of Psychopathology 
and Behavioral Assessment, 26, 41-54. doi:10.1023/ B:JOBA.0000007455.08539.94

Grøholt, B., Ekeberg, O., Wichstrøm, L., \& Haldorsen, T. (2000). Young suicide attempters: A comparison between a clinical and an epidemiological sample. Fournal of the American Academy of Child and Adolescent Psychiatry, 39, 868875. doi:10.1097/00004583-200007000-00015

Grunbaum, J. A., Kann, L., Kinchen, S. A., Williams, B., Ross, J. G., Lowry, R., ET al. (2002). Youth risk behavior surveillance - United States, 2001. Fournal of School Health, 72, 313 328. doi:10.1111/j.1746-1561.2002.tb07917.x

Guertin, T., Lloyd-Richardson, E., SpIrito, A., Donaldson, D., \& Boergers, J. (2001). Self-mutilative behavior in adolescents who attempt suicide by overdose. Fournal of the American Academy of Child and Adolescent Psychiatry, 40, 1062-1069. doi:10.1097/00004583-20010900000015

Harter, S. (1988). Manual for the self-perception profile for adolescents. Denver, CO: University of Denver.

Harter, S. (2012). Self-perception profile for adolescents: Manual and questionnaires. Denver, CO: University of Denver. Retrieved March 14, 2014, from https://portfolio.du.edu/downloadItem/221931

Hartshorne, T. S. (1993). Psychometric properties and confirmatory factor analysis of the UCLA loneliness scale. Fournal of Personality Assessment, 61, 182-195. doi:10.1207/s15327752jpa6101_ 14

JOINER, T. E. (2005). Why people die by suicide. Cambridge: Harvard University Press.

Klonsky, E. D., \& May, A. M. (2014). Differentiating suicide attempters from suicide ideators: A critical frontier for suicidology research. Suicide and Life-Threatening Bebavior, 44, 1-5. doi:10.1111/sltb.12068

Kolbe, L. J., Kann, L., \& Collins, J. L. (1993). Overview of the youth risk behavior surveillance system. Public Health Reports, 108(Suppl 2), 2-10.

Malone, K. M., Oquendo, M. A., Haas, G. L., Ellis, S. P., Li, S., \& Mann, J. J. (2000). Protective factors against suicidal acts in major depression: Reasons for living. The American Journal of Psychiatry, 157, 1084-1088.

Martin, G., \& Waite, S. (1994). Parental bonding and vulnerability to adolescent suicide. Acta Psychiatrica Scandinavica, 89, 246-254.

Matheson, K., Kelly, O., Cole, B., Tannenbaum, B., Dodd, C., \& Anisman, H. (2005). Parental bonding and depressive affect: The mediating role of coping resources. The British Journal of Social Psychology/The British Psychological Society, 44(Pt 3), 371-395. doi:10.1348/014466605 $\mathrm{X} 37477$
May, A., \& Klonsky, E. D. (2011). Validity of suicidality items from the Youth Risk Behavior Survey in a high school sample. Assessment, 18, 379-381. doi:10.1177/1073191110374285

Nock, M. K., Borges, G., Bromet, E. J., Cha, C. B., Kessler, R. C., \& Lee, S. (2008). Suicide and suicidal behavior. Epidemiologic Reviews, 30, 133-154. doi:10.1093/epirev/mxn002

Nock, M. K., Green, J. G., Hwang, I., Mclaughlin, K. A., Sampson, N. A., Zaslavsky, A. M., ET AL. (2013). Prevalence, correlates, and treatment of lifetime suicidal behavior among adolescents: Results from the National Comorbidity Survey Replication Adolescent Supplement. 7AMA Psychiatry, 70, 300-310. doi:10.1001/ 2013.jamapsychiatry.55

Nock, M. K., \& Prinstein, M. J. (2005). Contextual features and behavioral functions of selfmutilation among adolescents. Fournal of Abnormal Psychology, 114, 140-146. doi:10.1037/0021-843X. 114.1.140

O'Connor, R. C. (2011). Towards an integrated motivational-volitional model of suicidal behaviour. In R. C. O'Connor, S. Platt, \& J. Gordon (Eds.), International handbook of suicide prevention: Research, policy and practice (pp. 181198). Chichester, UK: John Wiley \& Sons.

PARker, G. (1990). The parental bonding instrument. Social Psychiatry and Psychiatric Epidemiology, 25, 281-282. doi:10.1007/BF00782881

Parker, G., Tupling, H., \& Brown, L. B. (1979). A parental bonding instrument. British Fournal of Medical Psychology, 52, 1-10. doi:10.1111/ j.2044-8341.1979.tb02487.x

Patton, G. C., Coffey, C., Sawyer, S. M., Viner, R. M., Haller, D. M., Bose, K., et al. (2009). Global patterns of mortality in young people: A systematic analysis of population health data. Lancet, 374, 881-892. doi:10.1016/S0140-6736(09) 60741-8

Pfeffer, C. R., Normandin, L., \& KaKuma, T. (1994). Suicidal children grow up: Suicidal behavior and psychiatric disorders among relatives. Fournal of the American Academy of Child and Adolescent Psychiatry, 33, 1087-1097. doi:10.1097/00004583-199410000-00004

Roberts, R. E., Roberts, C. R., \& Chen, Y. R. (1998). Suicidal thinking among adolescents with a history of attempted suicide. Fournal of the American Academy of Child and Adolescent Psychiatry, 37, 1294-1300. doi:10.1097/00004583199812000-00013

Russell, D. (1996). UCLA Loneliness Scale (Version 3): Reliability, validity, and factor structure. Fournal of Personality Assessment, 66, 20-40. doi:10.1207/s15327752jpa6601_2

Russell, D., Peplau, L. A, \& Cutrona, C. E. (1980). The revised UCLA Loneliness Scale: Concurrent and discriminant validity evi- 
dence. Fournal of Personality and Social Psychology, 39, 472-480. doi:10.1037/0022-3514.39.3.472

Ten Have, M., de Graaf, R., van DorsSelaer, S., Verdurmen, J., Van`T Land, H., VolLEBERGH, W., ET AL. (2009). Incidence and course of suicidal ideation and suicide attempts in the general population. Canadian Fournal of Psychiatry, $54,824-833$.

Todd, A., Boyce, P., Неath, A., \& Martin, N. (1994). Shortened versions of the interpersonal sensitivity measure, parental bonding instrument and intimate bond measure. Personality and Individual Differences, 16, 323-329. doi:10.1016/0191-8869(94)90169-4

Tousignant, M., Bastien, M. F., \& Hamel, S. (1993). Suicidal attempts and ideations among adolescents and young adults: The contribution of the father's and mother's care and of parental separation. Social Psychiatry and Psychiatric Epidemiology, 28, 256-261. doi:10.1007/BF007887 46

Tull, M. T., \& Roemer, L. (2007). Emotion regulation difficulties associated with the experience of uncued panic attacks: Evidence of experiential avoidance, emotional nonacceptance, and decreased emotional clarity. Behavior Therapy, 38, 378-391. doi:10.1016/j.beth.2006.10.006

Vassar, M., \& Crosby, J. W. (2008). A reliability generalization study of coefficient alpha for the UCLA Loneliness Scale. Fournal of Personality Assessment, 90, 601-607. doi:10.1080/ 00223890802388624

WeinberG, A., \& Klonsky, E. D. (2009). Measurement of emotion dysregulation in adolescents. Psychological Assessment, 21, 616-621. doi:10.1037/a0016669
Whitley, B. E., \& Kite, M. E. (2013). Principles of research in behavioral science (3rd ed.). Hove, East Sussex: Routledge.

Wichsтrøm, L. (1995). Harter's self-perception profile for adolescents: Reliability, validity, and evaluation of the question format. Fournal of Personality Assessment, 65, 100-116. doi:10.1207/s15327752jpa6501_8

WichstrøM, L. (2000). Predictors of adolescent suicide attempts: A nationally representative longitudinal study of Norwegian adolescents. Fournal of the American Academy of Child and Adolescent Psychiatry, 39, 603-610. doi:10.1097/ 00004583-200005000-00014

Wilhelm, K., Niven, H., Parker, G., \& Hadzi-Pavlovic, D. (2005). The stability of the Parental Bonding Instrument over a 20-year period. Psychological Medicine, 35, 387-393.

World Health Organization. (1999). Facts and figures about suicide. Geneva: World Health Organization Press Office. Retrieved March 15, 2014, from http://scholar.google.com/scholar? hl=en\&btnG=Search\&q=intitle:Facts+and+Figures+About+Suicide\#2

Zlotnick, C., Donaldson, D., Spirito, A., \& Pearlstein, T. (1997). Affect regulation and suicide attempts in adolescent inpatients. Fournal of the American Academy of Child and Adolescent Psychiatry, 36, 793-798. doi:10.1097/000045 83-199706000-00016

Manuscript Received: May 15, 2014

Revision Accepted: October 13, 2014 